\title{
Respuesta físico-química de la bahía de Valparaíso a la surgencia generada en punta Curaumilla y al fenómeno El Niño*
}

\author{
Physical-chemical response of Valparaíso Bay to upwelling generated \\ at Point Curaumilla and to El Niño Phenomenon \\ Hellmuth A. Sievers y Sergio A. Vega \\ Facultad de Ciencias del Mar, Universidad de Valparaíso. Casilla 13-D, Viña del Mar, Chile. \\ hellmuth.sievers@uv.cl
}

\begin{abstract}
Physical and chemical oceanographic data measured at 2-3 day intervals during November-December 1996 and 1997 in Valparaíso Bay were aimed to study interdaily and interannual water characteristics variability. Of particular interest were those related to upwelling generated at Point Curaumilla. The response of Valparaíso Bay to upwelling could be studied during a dry and relatively cold year (1996) and a warmer and rainy El Niño 1997/98 year (1997). Upwelled Equatorial Subsurface water, characterized by low temperature and dissolved oxygen and high salinity and nutrient concentrations, was advected into the bay replacing at times the Subantarctic water which normally fills it. The surface lowest temperatures and the highest salinity values in both years were similar during the mature stage of coastal upwelling periods.

The average sea surface temperature during non upwelling periods was higher in 1997 as compared to 1996 due to El Niño 1997/98. Salinity was much lower in 1997 while phosphate, nitrate and silicate concentrations were much higher, due to a considerable increase of the Aconcagua River discharge due to El Niño 1997/98.

Large interdaily fluctuations in the physical and chemical surface water characteristics at Valparaíso Bay could be observed during both periods. These fluctuations were subjected to complex interactions between the initial conditions, wind and pressure fields, upwelling stages and the Aconcagua River estuarine flow.
\end{abstract}

Keywords: oceanography, water masses, wind, Chile.
Resumen.- En los meses de noviembre-diciembre de 1996 y 1997 se efectuaron observaciones oceanográficas en la bahía de Valparaíso, a intervalos de 2-3 días, con el objeto de caracterizar la variabilidad interdiaria e interanual de distribución de sus características físicas y químicas, en especial con relación a episodios de surgencia costera generada en punta Curaumilla. La información registrada permitió estudiar la respuesta de la bahía de Valparaíso a episodios de surgencia durante un año seco y relativamente frío (1996) y uno más cálido y lluvioso (1997), año de ocurrencia del intenso fenómeno de El Niño 1997/98. Como consecuencia de los procesos de surgencia registrados en 1996 y 1997 se produjo una fuerte advección de agua Ecuatorial Subsuperficial hacia la bahía. Esta agua, caracterizada por bajos valores de temperatura y oxígeno disuelto, alta salinidad y concentraciones elevadas de nutrientes, prácticamente reemplazó en períodos de fuerte surgencia a la Subantártica que normalmente llena la bahía. Se puede observar también que durante las fases de madurez de la surgencia costera los valores superficiales más bajos de temperatura, al igual que los más altos en salinidad, fueron similares en ambos años.

La temperatura superficial promedio del mar, en períodos de ausencia de surgencia, fue mayor en 1997 que en 1996 debido a El Niño 1997/98. La salinidad, a su vez, fue menor en 1997 mientras que las concentraciones de nitrato, fosfato y silicato fueron claramente mayores. Estas diferencias tienen relación con el fuerte incremento del caudal del río Aconcagua debido a El Niño 1997/98.

Ambos períodos mostraron fuertes fluctuaciones interdiarias de las características físico-químicas superficiales dentro de la bahía, sujetas a complejas interacciones entre las condiciones iniciales, los campos de presión y viento, las distintas fases de surgencia y el flujo estuarino del río Aconcagua.

Palabras claves: oceanografía, masas de agua, viento, Chile.

\section{Introducción}

El estudio de la zona costera de la región de Valparaíso, en la cual se encuentran insertas la bahía y el puerto del mismo nombre, ha concitado desde hace tiempo el interés de meteorólogos y oceanógrafos. Sin embargo la bahía como tal ha sido poco estudiada como se desprende del trabajo de Avaria et al. (1989). En dicha revisión de los aspectos oceanográficos físicos, químicos y planctológicos de la región de Valparaíso sólo figuran tres trabajos en directa relación con la bahía. Estos son los de Pizarro (1976), Fonseca \& Hickmann (1978) y Sievers (1988). De éstos el único que describe toda la bahía es el de Fonseca \& Hickmann (1978), mientras los otros se concentraron principalmente en la zona frente a Montemar (Fig.1). 
Reconociendo la necesidad de contar con un mejor conocimiento de la hidrología de la bahía de Valparaíso se realizaron, durante dos períodos consecutivos de primavera (noviembre-diciembre de 1996 y 1997), observaciones oceanográficas y meteorológicas interdiarias. Las investigaciones se concentraron en dicho período del año, pues uno de los objetivos principales era poder determinar con más detalle la respuesta de las condiciones físicas y químicas a las distintas fases de la surgencia costera generada por los vientos del tercer cuadrante (S y SW), en punta Curaumilla.

Si bien dicha punta ha sido caracterizada como zona de surgencia y el radio de influencia de las aguas surgentes, sobre las zonas costeras adyacentes, ha sido parcialmente observado por diversos autores (Brandhorst 1963 y 1971, Sievers \& Silva 1973 y 1979, Silva 1973, Fonseca 1977, Uribe 1978, Johnson et al. 1980, Fonseca et al. 1988), no se habían realizado estudios orientados a determinar el nivel de influencia de estos procesos al interior de la bahía. Por otra parte, todas las investigaciones estuvieron basadas en observaciones espaciadas en el tiempo (i.e. Silva 1973, Sievers \& Silva 1979) o fueron de corta duración (i.e. Fonseca 1977). En cambio el presente estudio está basado en observaciones cada 2-3 días, secuencia que permitió obtener resultados más detallados.

Estudios realizados con imágenes satelitales de temperatura superficial en la zona de Valparaíso mostraron lenguas de aguas frías, producto de procesos de surgencia, que se extendían por 50, incluso $100 \mathrm{~km}$, desde punta Curaumilla al NW (Fonseca \& Farías 1987, Masotti 1999). Hacia el término de los procesos, de aproximadamente una semana de duración, se registraron ingresos de agua de $13{ }^{\circ} \mathrm{C}$ a la bahía (Fonseca \& Farías 1987). Al calcular los índices de surgencia para la zona, Montecinos \& Balbontín (1993) encontraron que estos fueron mayores en punta Ángeles que en Montemar, presentándose los máximos entre septiembre y enero, período de mayor frecuencia de vientos del $\mathrm{S}$ y SW, y los mínimos entre mayo y agosto.

Una situación extremadamente favorable para esta investigación se presentó en 1997 al ocurrir el fenómeno El Niño 1997/98. Considerado como el ENSO más intenso de este siglo permitió estudiar la variabilidad en las características oceanográficas y respuesta de la bahía a procesos de surgencia en un año seco y relativamente frío (1996) y otro cálido y lluvioso (1997) como también la influencia de un gran caudal del río Aconcagua sobre sus aguas superficiales como ocurrió en la primavera de 1997.

\section{Materiales y Métodos}

El estudio se efectuó en dos fases. La primera, realizada entre el 19 de noviembre y 9 de diciembre de 1996, consistió en observaciones de temperatura y salinidad con CTD (Sea Bird 9) en 6 estaciones (Fig. 1). Adicionalmente se obtuvieron muestras de agua con botellas Niskin a 0 y $10 \mathrm{~m}$ en la estación 6 , para determinar la concentración de fosfato, nitrato y silicato. Considerando que el CTD estaba bien calibrado se prescindió, en dicha oportunidad, del registro de temperatura con termómetros de inversión y toma de muestras de agua para la determinación de la salinidad. En esta primera fase no se observó contenido de oxígeno disuelto.

Para la segunda fase, realizada entre el 3 de noviembre y el 30 de diciembre de 1997, se consideró además de la prolongación del período de observación y uso del CTD, registro de temperatura y la toma de muestras de agua por el método tradicional (botellas Nansen) a 6 niveles entre superficie y fondo $(0,5,10$, 20,30 y $55 \mathrm{~m}$ ) en la estación 6 . Se seleccionó la estación 6 porque en dicha ubicación se ha estado recolectando información oceanográfica periódicamente (a lo menos quincenalmente) desde 1986 por la Facultad de Ciencias del Mar de la Universidad de Valparaíso.

Las muestras de salinidad fueron analizadas en el Servicio Hidrográfico y Oceanográfico de la Armada mediante un salinómetro digital marca Guildline Portasal modelo 8410. A su vez el oxígeno disuelto y los nutrientes fueron analizados en la Facultad de Ciencias del Mar. El primero por el método de Carrit \& Carpenter (1966) y los nutrientes por los métodos de Korolef (1983) para el fosfato, Grasshoff (1983) para el nitrato y Strikland \& Parsons (1968) para el silicato.

Con la información recolectada se prepararon gráficos de series de tiempo de los promedios registrados con CTD para las tres estaciones más oceánicas e individualmente para la estación 6 (figuras no incluidas). De esta forma se pudo comparar, además del estudio de la variabilidad interdiaria, el comportamiento general interanual entre 1996 y 1997 de las características del agua observadas, como asimismo contrastarlas con los datos obtenidos con botellas Nansen en la estación 6.

La información meteorológica, temperatura del aire, presión atmosférica, nubosidad y viento, proporcionada por el Servicio Meteorológico de la Armada, corresponde a observaciones efectuadas en el faro Punta Ángeles. Este faro se encuentra ubicado en el sector sur de la bahía de Valparaíso a $60 \mathrm{~m}$ sobre el nivel del mar (Fig. 1). Con dichos datos se prepararon series de tiempo, utilizándose para el viento solamente la 
componente norte-sur, por ser aquella la de mayor incidencia sobre los procesos de surgencia.

Datos diarios del caudal del río Aconcagua, correspondientes a la estación fluviométrica Chacabuquito (Los Andes), fueron proporcionados por la Dirección Regional de Aguas, Región de Valparaíso. Si bien el caudal registrado en dicho punto de medición, alejado de la costa y a una altura de $1030 \mathrm{~m}$ sobre el nivel del mar, no corresponde al volumen de agua que efectivamente llega al océano es una buena referencia del que puede esperarse en la desembocadura del río Aconcagua.
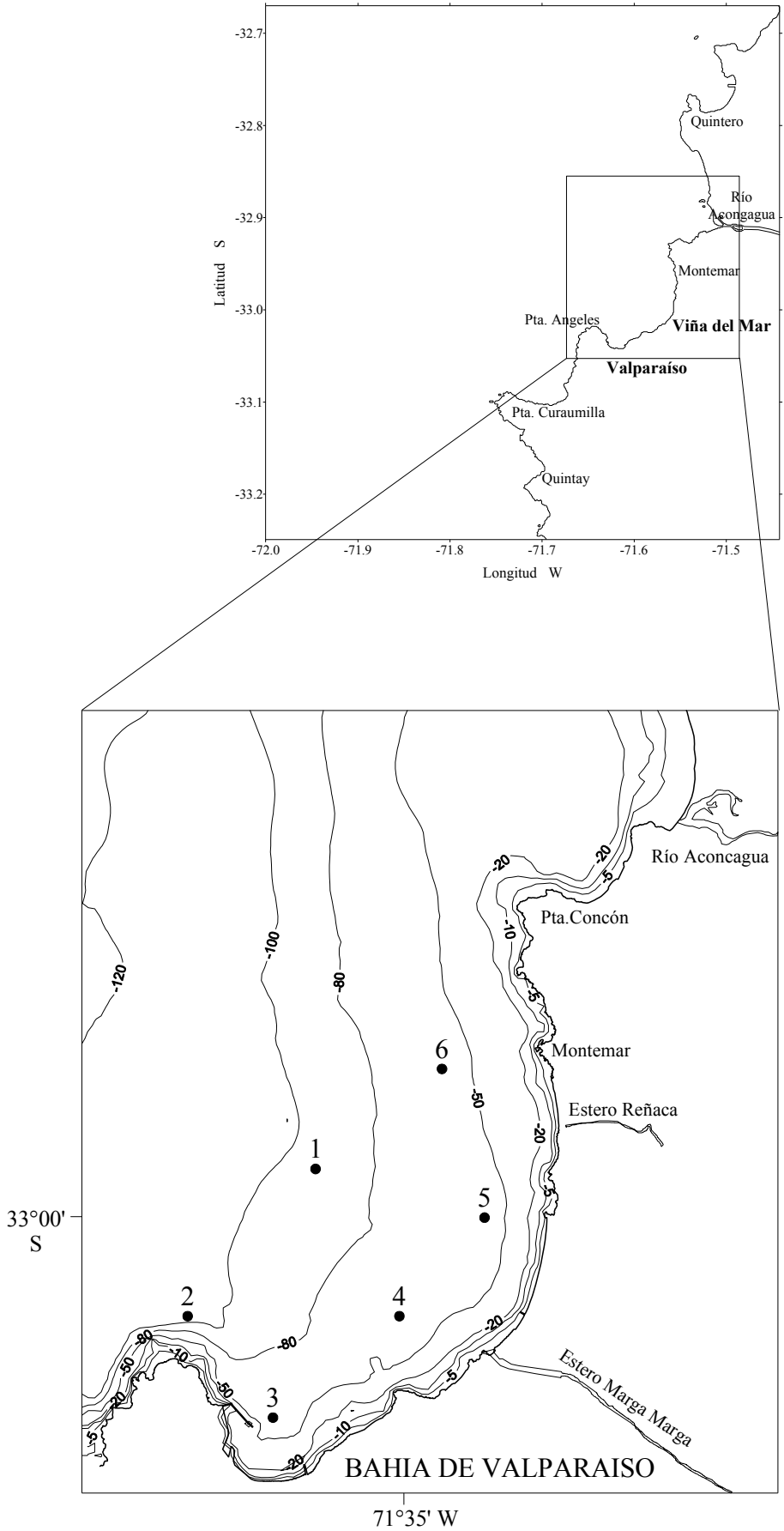

Figura 1

Ubicación geográfica de las estaciones oceanográficas en la bahía de Valparaíso.

Location of the oceanographic stations in Valparaíso Bay. 


\section{Resultados}

\section{Temperatura}

En la época común de observación se presentaron pocas diferencias interanuales de temperatura en la bahía de Valparaíso durante las fases de surgencia, cuyos valores promedios próximos a la superficie fueron del orden de
$13{ }^{\circ} \mathrm{C}$. En profundidad tampoco se presentaron mayores diferencias, excepción hecha de la isoterma de $12{ }^{\circ} \mathrm{C}$ que se encontró algo más profunda en la primavera de 1997 (Figs. 2 y 3). En cambio durante fases de calma o vientos suaves del norte se registraron temperaturas superficiales más altas $\left(>16^{\circ} \mathrm{C}\right)$, como también una mayor profundización de las isotermas. Este efecto se vio acentuado en 1997 (año de El Niño 1997/98) en
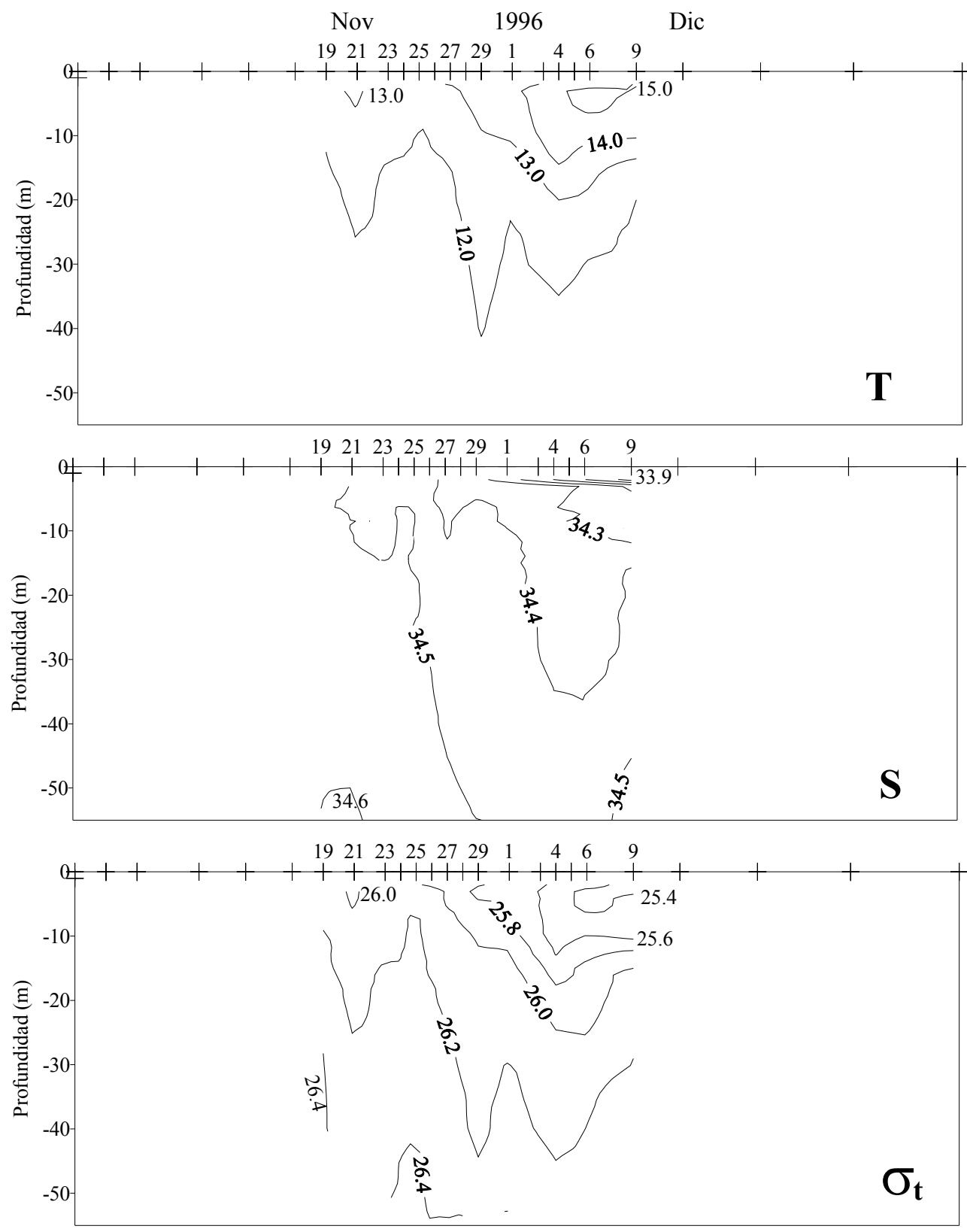

Figura 2

Distribución de los promedios de temperatura $\left({ }^{\circ} \mathrm{C}\right)$, salinidad (PSU) y densidad $\left(\sigma_{\mathrm{t}}, \mathrm{kg} \mathrm{m}^{-3}\right)$ observados con CTD en las estaciones 1, 2 y 6, entre el 19 de noviembre y el 9 de diciembre de 1996, en la bahía de Valparaíso.

Distribution of the averaged temperature $\left({ }^{\circ} \mathrm{C}\right)$, salinity (PSU), and density $\left(\sigma_{\mathrm{t}}, \mathrm{kg} \mathrm{m}^{-3}\right)$ measured with CTD at stations $1,2 \mathrm{y} 6$ from 19 November to 9 December 1996 in Valparaíso Bay. 

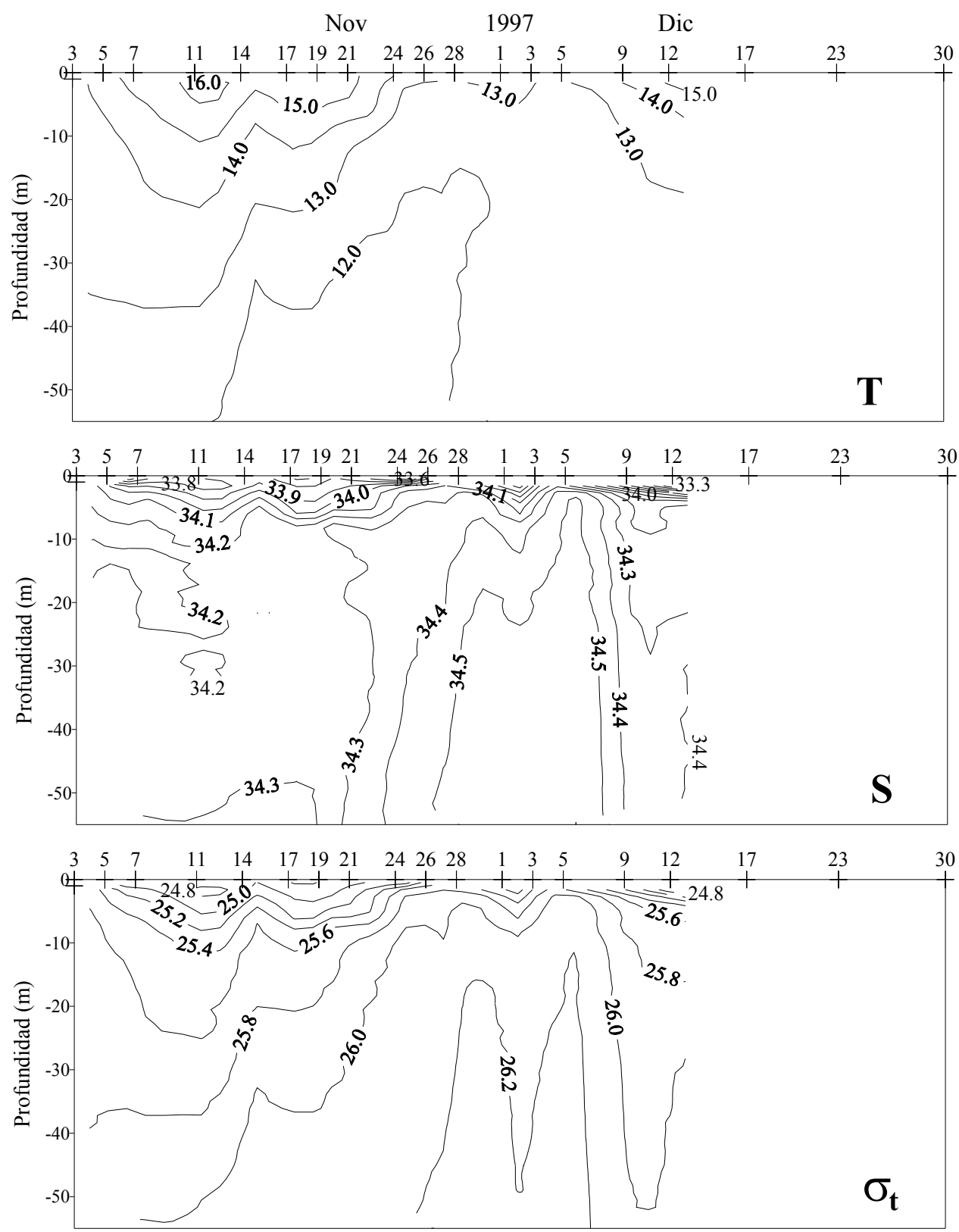

Figura 3

Distribución de los promedios de temperatura $\left({ }^{\circ} \mathrm{C}\right)$, salinidad (PSU) y densidad $\left(\sigma_{t}, \mathrm{~kg} \mathrm{~m}^{-3}\right)$ observados con CTD en las estaciones 1, 2 y 6, entre el 3 de noviembre y el 12 de diciembre de 1997, en la bahía de Valparaíso.

Distribution of the averaged temperature $\left({ }^{\circ} \mathrm{C}\right)$, salinity (PSU), and density $\left(\sigma_{\mathrm{t}}, \mathrm{kg} \mathrm{m}^{-3}\right)$ measured with CTD at stations 1,2 y 6 from 3 November to 12 December 1997 in Valparaíso Bay.

que, por ejemplo, la isoterma de $13{ }^{\circ} \mathrm{C}$, se encontró aproximadamente $10 \mathrm{~m}$ más profunda que en 1996. Una comparación similar para la estación 6 indica que las temperaturas superficiales más bajas registradas durante el período de observación fueron 12,4 y $11,8{ }^{\circ} \mathrm{C}$ y las más altas 15,6 y $17,6{ }^{\circ} \mathrm{C}$ para 1996 y 1997 respectivamente. La última más alta indicada se registró hacia fines de diciembre de 1997 (Fig. 4a).

Como observación general cabe destacar la gran variabilidad, tanto en la distribución de temperatura superficial como vertical con ascensos y hundimientos de las isotermas, movimientos que estuvieron asociados directamente con los períodos de surgencia, los primeros, y fases de calma, los segundos.

\section{Salinidad}

La salinidad superficial presentó una gran variabilidad interanual. En la primavera de 1996 las concentraciones promedio en las tres estaciones variaron entre 34,3 y 34,5 PSU con un valor muy bajo ( $<33,9$ PSU) al final del 
período de observación (Fig. 2). En 1997 la salinidad superficial fue bastante menor, registrándose concentraciones promedio menores de 33,8 PSU durante la mayor parte del período de observación. El más bajo (33,3 PSU) se registró el 12 de diciembre (Fig. 3). Las menores salinidades se presentaron en la estación 6 donde, por lo menos en una oportunidad (28 de noviembre de 1997), fue incluso inferior a 30 PSU (Fig. 4b).

La distribución vertical de la salinidad también presentó diferencias entre uno y otro año apreciándose que durante períodos de calma, y al igual que en superficie, su concentración media fue menor en 1997 $(<34,3$ PSU ) en toda la columna de agua (Figs. 2 y 3 ). Durante la ocurrencia de procesos de surgencia la salinidad presentó valores similares en ambos años (> 34,5 PSU), concentraciones que se mantuvieron altas en 1996, incluso con posterioridad al término de dicho proceso.

Al igual que en el caso de la temperatura se produjeron ascensos y hundimientos de las isohalinas coincidentes con los procesos de surgencia y fases de calma, respectivamente.

\section{Densidad}

Las densidades próximas a la superficie presentaron más variabilidad en la primavera de 1996 que al año siguiente, disminuyendo de valores superiores a 26,0 durante los procesos de surgencia a menos de 25,4 durante la fase de calma (Fig. 2). En cambio en 1997 la densidad fue, en general, más baja, incluso menor a 25,0 debido principalmente a la baja salinidad superficial (Fig. 3).

En profundidad se presentaron fluctuaciones verticales de las isopicnas, asociados los descensos a las fases de calma y los ascensos, algunos muy marcados (ej.: $\sigma_{\mathrm{t}}=26,0$ y 26,2), a los procesos de surgencia (Figs. 2 y 3). De las figuras, especialmente de la 3 , se desprende también la forma en que las isopicnas siguieron patrones diferentes en períodos de calma, oportunidad en que se asemejaron más al de las isotermas, que en períodos de surgencia en que se ajustaron bastante bien al de las isohalinas.

\section{Oxígeno disuelto}

El contenido de oxígeno disuelto sólo fue determinado en la estación 6 durante el crucero de primavera de 1997. De esta información se desprende que en superficie su contenido fluctuó entre 4,84 y $6,92 \mathrm{~mL} \mathrm{~L}^{-1}$ (Fig. 4c).

En cuanto a su distribución vertical, esta siguió un patrón muy parecido al de la salinidad, con ascensos y hundimientos de las isolíneas de oxígeno disuelto coincidentes en el tiempo y muy similares en su forma a las isohalinas, pero inversa respecto a sus concentraciones (Fig. 4). El contenido de oxígeno más bajo, registrado el 28 de noviembre de 1997, fue de $1,08 \mathrm{~mL} \mathrm{~L}^{-1}$ (18\% de saturación) a $55 \mathrm{~m}$ de profundidad.

\section{Nutrientes}

$\mathrm{Si}$ bien se registraron nutrientes (fosfato, nitrato y silicato) en la estación 6 durante los cruceros de primavera de 1996 sólo se tomaron muestras a 0 y $10 \mathrm{~m}$ de profundidad, pues estaban orientadas principalmente al estudio del fitoplancton. Las concentraciones extremas (mínimos y máximos) en las dos profundidades correspondientes al período común de observación se indican en la Tabla 1. De dicha tabla se desprende que se presentaron pocas variaciones interanuales en las concentraciones mínimas. Esto fue especialmente notorio para el silicato cuyas concentraciones superficiales mínimas fueron prácticamente cero, en ambos años. En cambio las máximas, con excepción del fosfato, fueron más altas durante la primavera de 1997. El caso más notable fue el del silicato que presentó concentraciones hasta ocho veces mayores en 1997 que las del año anterior.

También a $10 \mathrm{~m}$ de profundidad hubo bastante similitud en las concentraciones mínimas. En cuanto a las máximas las diferencias entre uno y otro año fueron menos marcadas que aquellas en la superficie apreciándose, con excepción del fosfato cuyas concentraciones fueron iguales, que las del nitrato y silicato fueron mayores en 1997. A su vez, las concentraciones tanto mínimas como máximas de fosfato y nitrato fueron más altas a $10 \mathrm{~m}$ de profundidad que en superficie. Distinto fue el caso del silicato cuyas concentraciones mínimas a $10 \mathrm{~m}$, al igual que en superficie, fueron prácticamente cero. Las concentraciones más altas, en cambio, siguieron siendo las superficiales que alcanzaron un valor de hasta $48,9 \mu \mathrm{mol} \mathrm{dm}^{-3}$ en 1997 (Tabla 1).

\section{Tabla 1}

Concentraciones mínimas y máximas de nutrientes en $\mu \mathrm{mol} \mathrm{dm}^{-3}$ en superficie y a $10 \mathrm{~m}$ de profundidad registradas en la estación 6, bahía de Valparaíso, en noviembre y diciembre de 1996 y en igual periodo de 1997.

Mínimum and maximum nutrient concentrations in $\mu \mathrm{mol} \mathrm{dm}{ }^{-3}$ at the surface and at $10 \mathrm{~m}$ depth measured at Station 6, Valparaíso Bay, in November and December 1996 and in the same period in 1997.

\begin{tabular}{ll|ll|rl}
\hline & & \multicolumn{2}{|c|}{ Superficie } & \multicolumn{2}{c}{$10 \mathrm{~m}$} \\
Nutriente & Año & 1996 & 1997 & 1996 & 1997 \\
\hline \multirow{2}{*}{ Fosfato } & Min. & 0,74 & 0,37 & 0,84 & 0,58 \\
& Max. & 2,23 & 2,37 & 3,60 & 3,62 \\
\multirow{2}{*}{ Nitrato } & Min. & 0,2 & 0,8 & 1,3 & 1,0 \\
& Max. & 3,6 & 8,5 & 5,7 & 11,5 \\
Silicato & Min. & 0,1 & 0,1 & 0,1 & 0,1 \\
& Max. & 6,2 & 48,9 & 12,3 & 19,6 \\
\hline
\end{tabular}


Nov $\quad 1997 \quad$ Dic

(a)

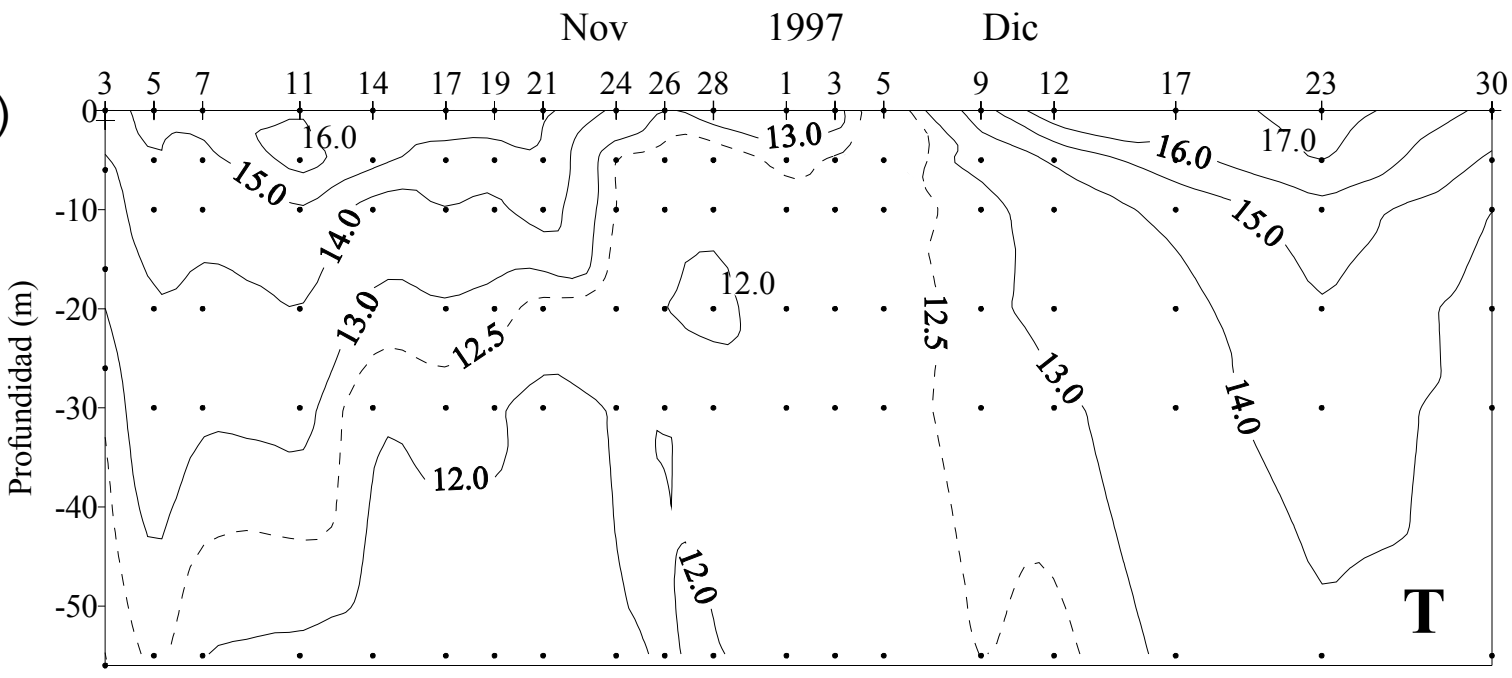

(b)

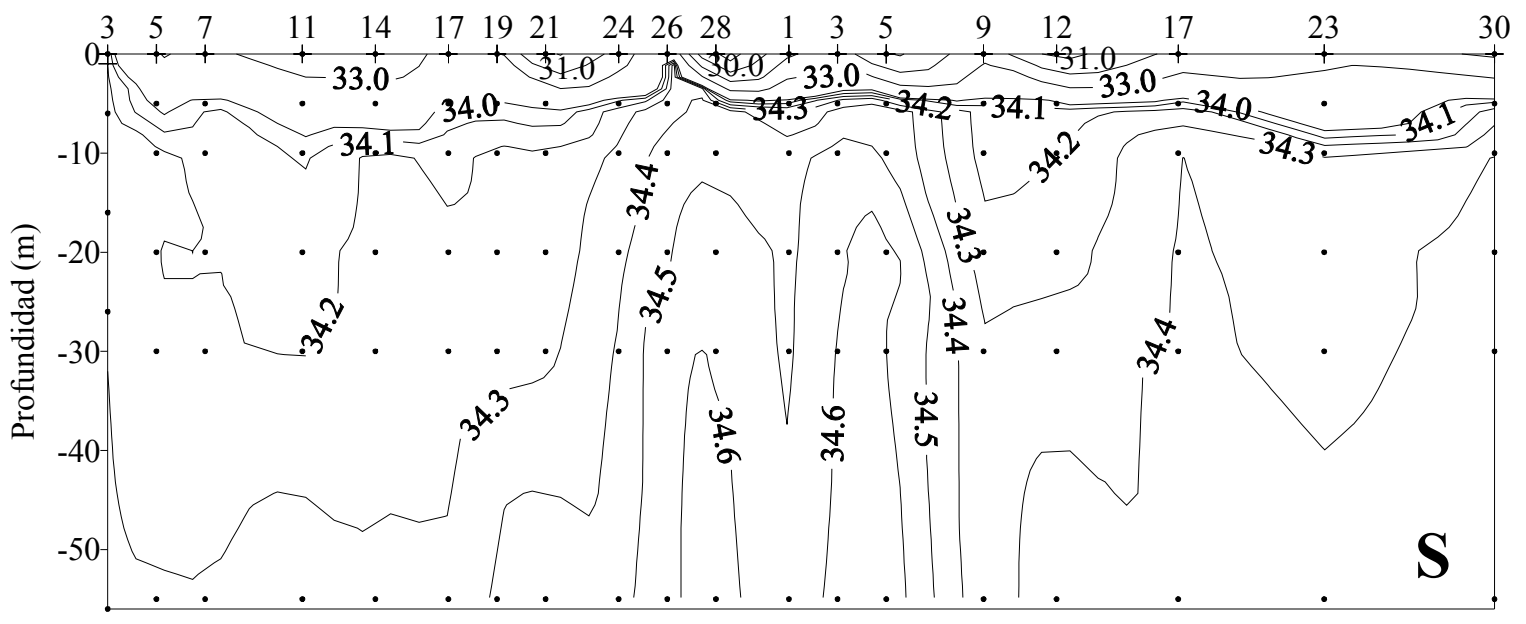

(c)

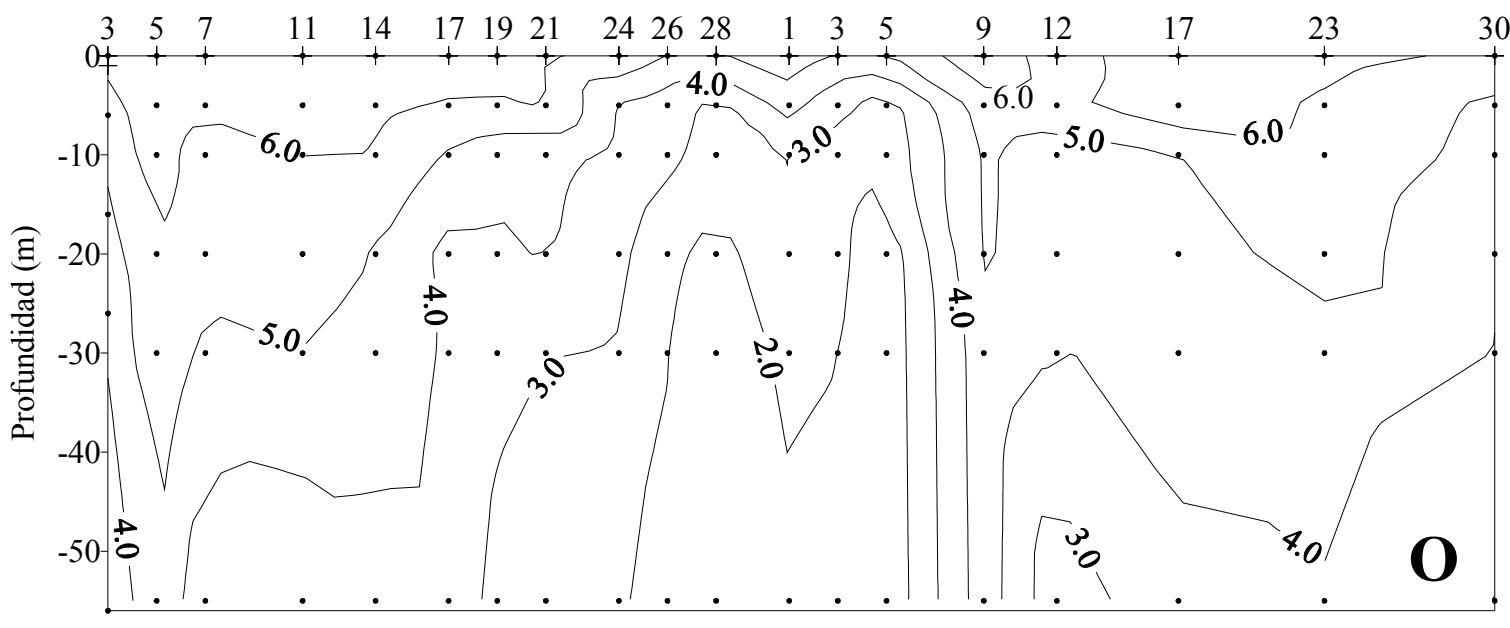

Figura 4

Distribución de (a) temperatura $\left({ }^{\circ} \mathrm{C}\right)$, (b) salinidad (PSU) y (c) oxígeno disuelto ( $\left.\mathrm{mL} \mathrm{L} \mathrm{L}^{-1}\right)$ en la bahía de Valparaíso, estación 6, noviembre - diciembre de 1997.

(a) Temperature $\left({ }^{\circ} \mathrm{C}\right)$, (b) salinity (PSU) and (c) dissolved oxygen $\left(\mathrm{mL} \mathrm{L}^{-1}\right)$ distribution in Valparaíso Bay, Station 6, NovemberDecember 1997. 
(d)

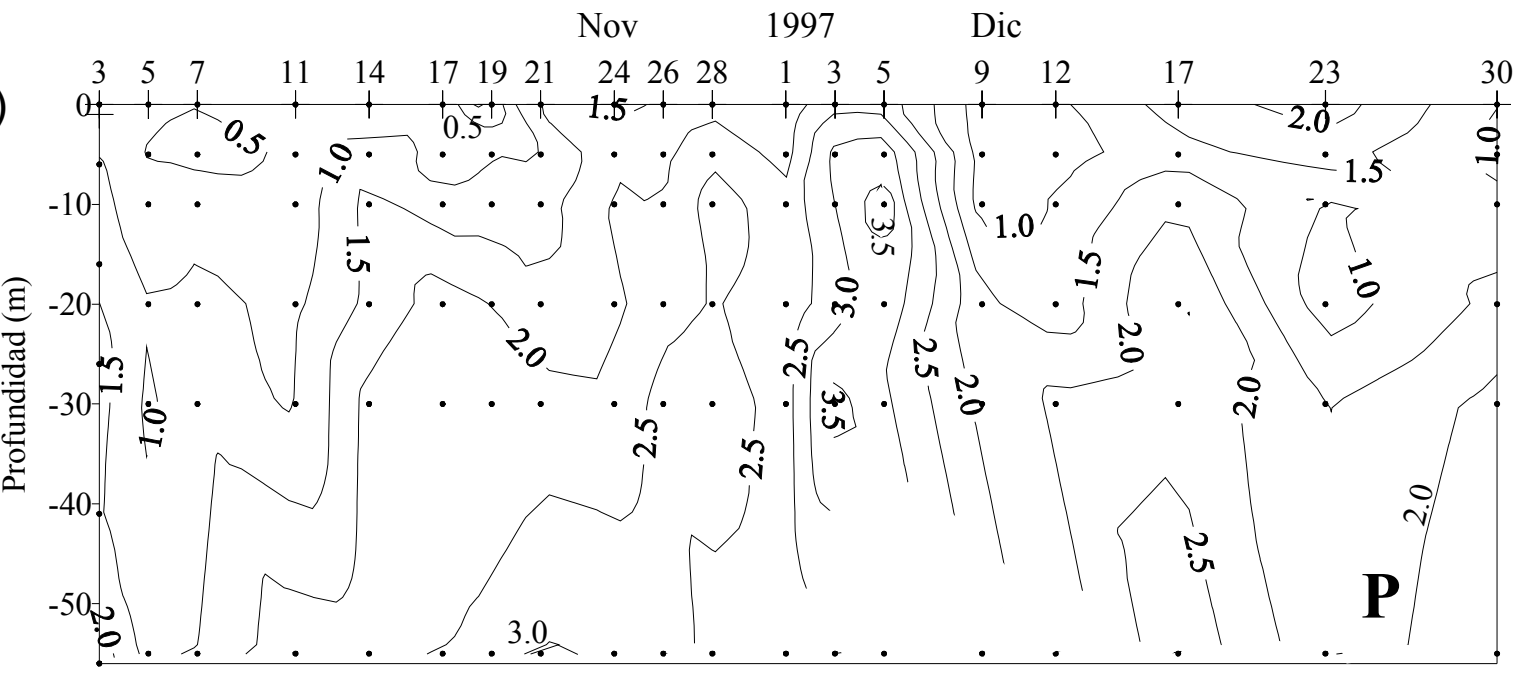

(e)

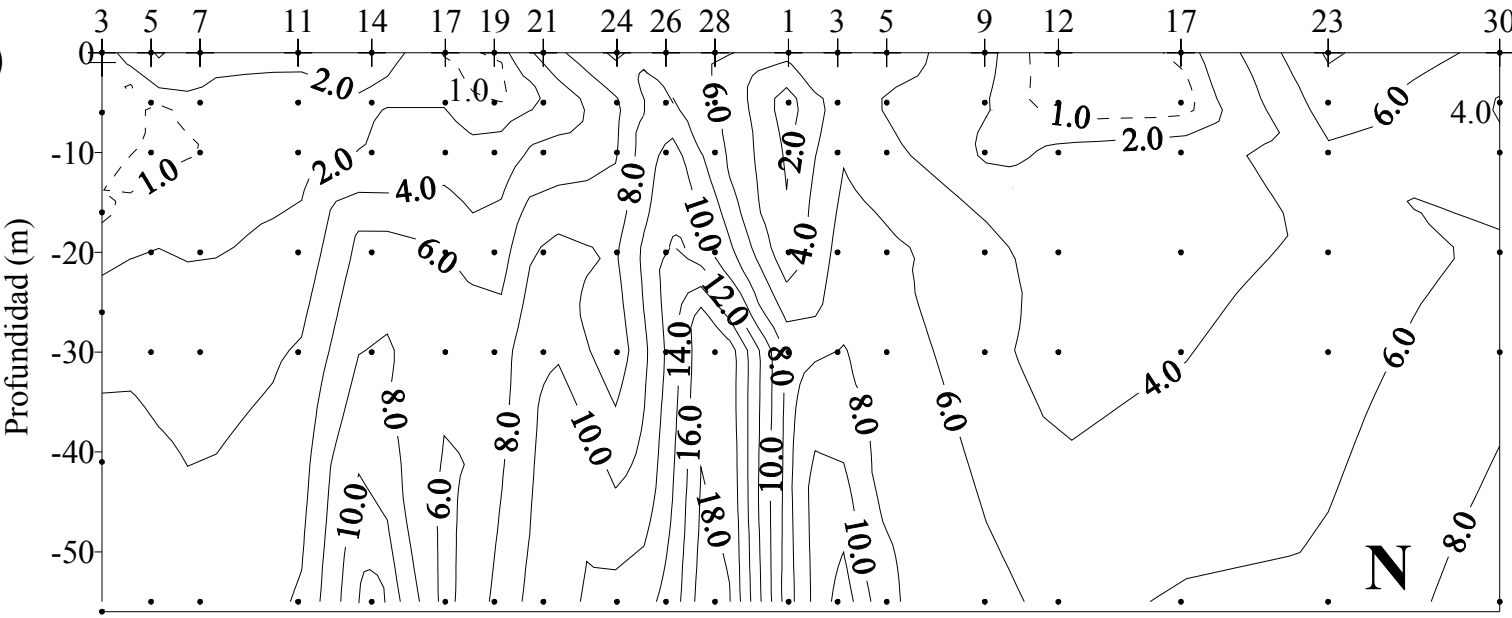

(f)

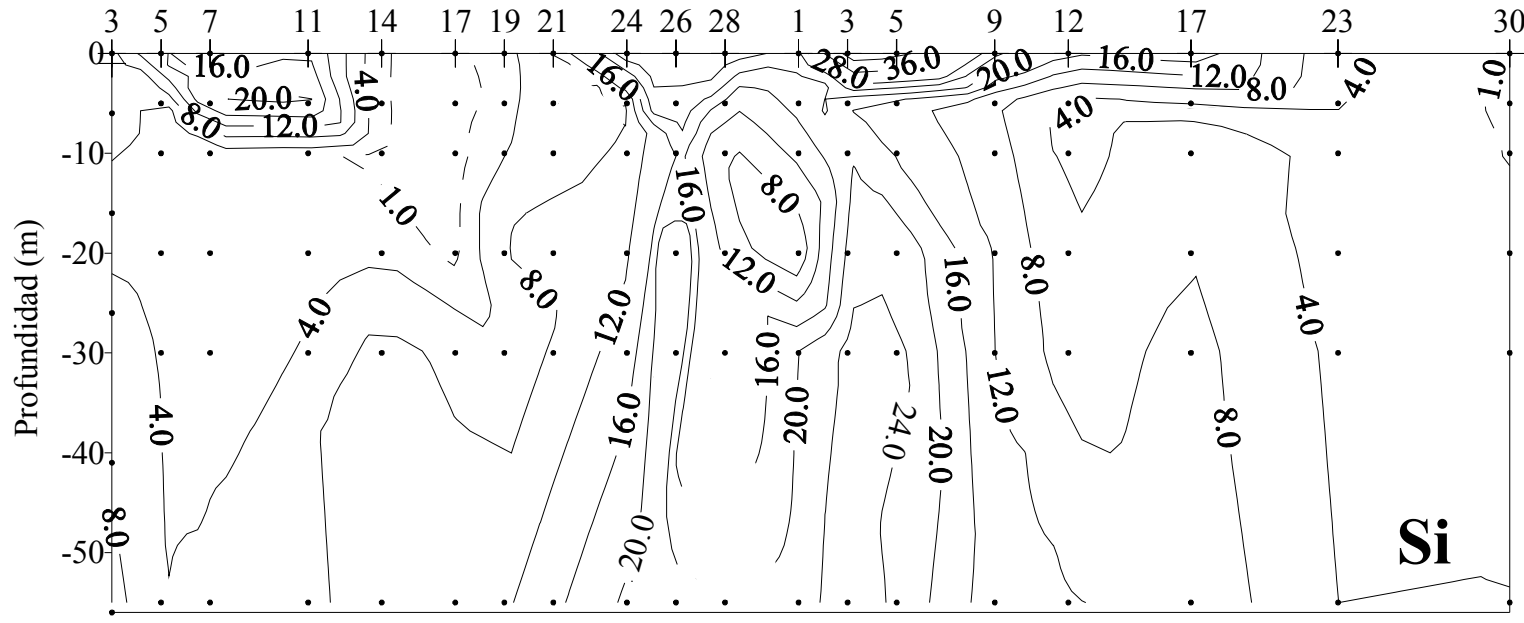

Figura 4 (cont.)

Distribución de (d) fosfato, (e) nitrato y (f) silicato en $\mu \mathrm{mol} \mathbf{d m}^{-3}$ en la bahía de Valparaíso, estación 6, noviembre-diciembre de 1997.

(d) Phosphate, (e) nitrate and (f) silicate in $\mu \mathrm{mol} \mathrm{dm}{ }^{-3}$ distribution in Valparaíso Bay, Station 6, November-December 1997. 
Una información más detallada de la distribución y variabilidad interdiaria de los nutrientes se obtuvo de las observaciones efectuadas, entre superficie y fondo en la estación 6 durante noviembre y diciembre de 1997 (Fig. $4 \mathrm{~d}, \mathrm{e}, \mathrm{f})$. Con excepción del nitrato, que presentó un mínimo de $0,1 \mu \mathrm{mol} \mathrm{dm}{ }^{-3}$ no hubo otras variaciones en las concentraciones mínimas y máximas superficiales respecto a las ya indicadas en la Tabla 1 .

De la distribución vertical de las concentraciones de nutrientes se aprecia gran variabilidad interdiaria, bastante coincidente y semejante con la ya observada para las características de temperatura, salinidad y oxígeno disuelto, clara indicación que esta se debe a los mismos procesos (Fig. 4). En cuanto a las concentraciones más altas se encontraron las del silicato en aguas superficiales (hasta $48,9 \mu \mathrm{mol} \mathrm{dm} \mathrm{dm}^{-3}$ ), las del fosfato $\left(3,72 \mu \mathrm{mol} \mathrm{dm} \mathrm{dm}^{-3}\right)$ en aguas intermedias $(\sim 30 \mathrm{~m})$ y las del nitrato $\left(20,9 \mu \mathrm{mol} \mathrm{dm}{ }^{-3}\right)$ próximas al fondo $(55 \mathrm{~m})$. Lo anterior no excluyó la presencia de máximos y mínimos relativos en la distribución vertical de estas características.

\section{Discusión}

La revisión de las características oceanográficas de la región de Valparaíso preparada por Avaria et al. (1989) constituye una buena base para estudiar la respuesta de la bahía a los procesos de surgencia generados en punta Curaumilla, como también al fenómeno El Niño.

En la región se presentan cuatro masas de agua que de superficie a fondo son: Subantártica, Ecuatorial Subsuperficial, Intermedia Antártica y Profunda del Pacífico (Avaria et al. 1989). Adicionalmente Prado \& Sievers (1987) detectaron la presencia de agua Subtropical en la región, consecuencia del fenómeno El Niño 1982/83. De las masas de agua indicadas, cuyas características fueron resumidas por Avaria et al. (1989) interesan particularmente las dos primeras pues son las que penetran a la bahía de Valparaíso. La primera, la Subantártica, que se extiende entre la superficie y aproximadamente $100 \mathrm{~m}$ de profundidad, se caracteriza por temperaturas moderadas $\left(11\right.$ a $\left.18{ }^{\circ} \mathrm{C}\right)$, salinidades relativamente bajas (34,0 a 34,5 PSU), alto contenido de oxígeno disuelto $\left(3\right.$ a $\left.7 \mathrm{~mL} \mathrm{~L}^{-1}\right)$ y concentraciones de nutrientes normalmente pobres, especialmente en superficie, que van aumentando con la profundidad. Entre aproximadamente 100 y $400 \mathrm{~m}$ de profundidad se encuentra la segunda, el agua Ecuatorial Subsuperficial que se caracteriza por temperaturas entre 7 y $11{ }^{\circ} \mathrm{C}$, salinidad relativamente alta (34,5 a 34,9 PSU), muy bajo contenido de oxígeno disuelto $\left(3 \mathrm{a} 0,25 \mathrm{~mL} \mathrm{~L}^{-1}\right)$ y altas concentraciones de nutrientes. Respecto al oxígeno cabe consignar que este puede ser aún más bajo, como pudieron constatar Silva \& Ramírez (1983) al registrar, frente a Valparaíso en diciembre de 1982, un contenido de sólo $0,01 \mathrm{~mL} \mathrm{~L}^{-1}$ ( $1 \%$ de saturación) a $289 \mathrm{~m}$ de profundidad. El bajo contenido de oxígeno siempre va asociado, en esta masa de agua, a valores altos de salinidad, característica que facilita mucho su identificación.

\section{Surgencia}

El inicio de las observaciones en 1996 coincidió con el desarrollo de un proceso de surgencia forzado por vientos del sur de 15 a $20 \mathrm{~m} \mathrm{~s}^{-1}$. Corroboración de lo anterior se obtuvo de imágenes de temperatura superficial del mar del satélite NOAA, particularmente de aquella del 19 de noviembre de 1996. En ella se observó que aguas de una lengua fría, que se extendía desde una zona al sur de punta Curaumilla hasta Quintero, ingresaba sólo parcialmente a la bahía de Valparaíso (Calderón 1998, Masotti 1999). Los valores de CTD promediados para las estaciones 1,2 y 6 acusaron esta disminución de la temperatura del agua $\left(\sim 12{ }^{\circ} \mathrm{C}\right)$, disminución que coincidió con salinidades y densidades altas (34,5 PSU y > 26,0) (Fig. 2).

La disminución en intensidad del viento los días 20 y 21 de noviembre $\left(\sim 10 \mathrm{~m} \mathrm{~s}^{-1}\right)$ dio paso a una corta fase de relajamiento seguida por una nueva intensificación de éste (Fig. 5). Una imagen del 22 de noviembre, coincidente con la fase de relajamiento de la surgencia, permitió observar que el área de bajas temperaturas superficiales había sido reemplazada por aguas más cálidas. Una reintensificación del viento los días 22 a 24 ocasionó una nueva baja de la temperatura superficial. Este enfriamiento alcanzó a insinuarse tenuemente en una imagen obtenida el 23, pero afectando una zona más alejada de la costa y hacia el norte de la bahía de Valparaíso. A su vez, el relajamiento y posterior intensificación de la surgencia se reflejó en la bahía, primero por un hundimiento seguido de un nuevo ascenso de las isolíneas, particularmente las de temperatura y densidad, y el consiguiente aumento y disminución de la temperatura superficial (Fig. 2). La alta salinidad (> 34,6 PSU) registrada, incluso próxima a la superficie en la primera fase del proceso en las estaciones 4 y 5 (valores no incluidos en el promedio), no volvió a presentarse al intensificarse éste nuevamente.

El debilitamiento, incluso inversión del viento a componente norte en días posteriores, se reflejó en el hundimiento de las isolíneas, un aumento de temperatura y la disminución de la salinidad y densidad en la capa superficial. Este aumento de temperatura también pudo observarse en las imágenes satelitales con las cuales se volvió a contar a partir del 30 de noviembre de 1996 (Calderón 1998, Masotti 1999).

El estudio de la respuesta de la bahía de Valparaíso a los procesos de surgencia en punta Curaumilla en 1996, 
si bien estableció algunas relaciones interesantes, especialmente aquellas propuestas por Calderón (1998), adolecieron de suficiente información para lograr resultados más esclarecedores. Así, con el objeto de poder estudiar a lo menos un ciclo completo de surgencia, se programó un período de observación de dos meses (noviembre y diciembre de 1997).

La comparación de la distribución de los valores promedios de temperatura y salinidad determinados con CTD para las estaciones 1, 2 y 6 (Fig. 3) con los registrados por métodos tradicionales en la estación 6 (Fig. 4) indica que son semejantes. Esto permitió asumir que esta última caracterizaba en forma adecuada la oceanografía de la bahía de Valparaíso y que el análisis de la respuesta de dicha bahía a los procesos de surgencia, podía realizarse en base a la información registrada en la estación 6. La distribución de las características del agua, que incluyen concentraciones de nutrientes, indica que se cumplió con el objetivo propuesto, pues se pudo seguir en todas sus fases (ausencia, formación, madurez, relajamiento y nuevamente ausencia) los efectos de un proceso de surgencia en la bahía de Valparaíso (Fig. 4).

Al iniciarse las observaciones en la primavera de 1997 las aguas de la bahía, identificadas por sus características como subantárticas, se encontraban estratificadas verticalmente con temperaturas superficiales relativamente altas $\left(\sim 16^{\circ} \mathrm{C}\right)$ y la presencia de una termoclina estacional (Fig. 4). El componente sur del viento medido en Punta Ángeles era moderado, con intensidades entre 5 y $10 \mathrm{~m} \mathrm{~s}^{-1}$. En momentos se registraron incluso vientos suaves del norte y alto porcentaje de nubosidad (Fig. 6). Las condiciones correspondían claramente a un período de ausencia de surgencia. La situación comenzó a cambiar al intensificarse, a contar del 14 de noviembre, el componente sur del viento $\left(>15 \mathrm{~m} \mathrm{~s}^{-1}\right)$ y presentarse cielos claros. Un ascenso de las isolíneas, aún cuando no se habían registrado todavía grandes cambios en las características superficiales del agua en la bahía, acusó la fase de inicio de un proceso de surgencia. Como consecuencia de este desplazamiento vertical se produjo, próxima al fondo, una penetración de aguas de origen ecuatorial subsuperficial, reflejada en una disminución de la temperatura $\left(<12{ }^{\circ} \mathrm{C}\right) \mathrm{y}$ del oxígeno disuelto $\left(<4 \mathrm{~mL} \mathrm{~L}^{-1}\right)$ y un aumento en las concentraciones de la salinidad ( $>34,3$ PSU) y los nutrientes (Fig. 4). Entre estos últimos el más notorio y proporcionalmente mayor aumento se produjo en el nitrato cuya concentración alcanzó valores de más de 12 $\mu \mathrm{mol} \mathrm{dm}{ }^{-3}$ (Fig. 4e).

Una disminución en la intensidad del viento entre el 17 y 21 de noviembre produjo una pausa en el movimiento ascendente de las isolíneas y un cambio a una orientación más horizontal de éstas (Fig. 6). Al intensificarse nuevamente, a contar del 22 , se reinició el ascenso de las isolíneas, dando paso al pleno desarrollo de una surgencia y sus efectos sobre las aguas de la bahía de Valparaíso (Fig. 4). La información disponible no permitió determinar el lapso transcurrido entre el momento de intensificación del viento, la iniciación del proceso de surgencia en punta Curaumilla, y sus efectos sobre las aguas de la bahía. En todo caso, de la distribución de las isolineas se desprende que el proceso se encontraba en pleno desarrollo el día 24 (Fig. 4). La disminución de la temperatura asociada a una alta salinidad ( $>$ 34,6 PSU), bajo contenido de oxígeno disuelto $\left(<2,0 \mathrm{~mL} \mathrm{~L}^{-1}\right)$ y alta concentración de nutrientes ( $>3,0 \mu \mathrm{mol} \mathrm{dm}^{-3}$ en fosfato, $>20 \mu \mathrm{mol} \mathrm{dm}$ en nitrato y $>20 \mu \mathrm{mol} \mathrm{dm}{ }^{-3}$ en silicato) indicaron que el agua que prácticamente llenó la bahía, como consecuencia de este período de surgencia fue agua Ecuatorial Subsuperficial (Avaria et al. 1989).

Situaciones similares habían sido observadas por Sievers (1988) y Sievers \& Prado (1990) en la misma zona de la estación 6 . En ocasiones las características del agua fueron incluso más acentuadas como por ejemplo un contenido de oxígeno disuelto menor de $1 \mathrm{~mL} \mathrm{~L}^{-1} \mathrm{o}$ nitrato en concentraciones mayores de $25 \mu \mathrm{mol} \mathrm{dm}{ }^{-3}$, indicativos que pudieron ocurrir procesos de surgencia más intensos que los registrados en 1996 y 1997.

El término de la acción forzante del viento, al producirse una brusca caída de intensidad a contar del 5 de diciembre se vio reflejado, a su vez, en un rápido descenso de las isolíneas, un aumento de la temperatura superficial, la restauración de la termoclina estacional $\mathrm{y}$, en general, el regreso a las condiciones iniciales previas al proceso descrito. Una intensificación del viento hacia fines de diciembre produjo un nuevo ascenso de las isolíneas, indicación que estaba comenzando un nuevo proceso de surgencia.

Calderón (1998) encontró que los eventos de depresión costera en la región de Valparaíso, con máxima intensificación de los vientos del tercer cuadrante durante el descenso de la presión, ocurren en escalas de tiempo de cinco a siete días, delimitados por dos o tres días de nubosidad costera (predominantemente estratocúmulos) y vientos del norte, situación que con algunas variantes también se repitió en 1997 (Fig. 6).

\section{Efectos de El Niño 1997/98}

En Avaria et al. (1989) se resumieron los efectos que el fenómeno de El Niño ejerce sobre el clima, siendo el más notorio un aumento considerable en las precipitaciones. En cambio los efectos sobre las condiciones oceanográficas en la región de Valparaíso han sido poco estudiados. Avaria et al. (1989) sólo citan 
dos trabajos que tienen relación con dicho fenómeno, específicamente el de 1982/83, que son los de Silva \& Ramírez (1983) y Prado \& Sievers (1987). Silva \& Ramírez (1983) observaron que la isoterma de $12{ }^{\circ} \mathrm{C}$ descendió en enero de 1983 hasta $300 \mathrm{~m}$, sobrepasando en más del triple la profundidad media histórica. Al mismo tiempo se produjo una intensificación de las características del agua Ecuatorial Subsuperficial y una anomalía positiva del geopotencial.

Prado \& Sievers (1987) estudiaron el desarrollo de este mismo fenómeno frente a Quintero (Fig. 1). Además de constatar anomalías en las características del agua (aumento de temperatura, disminución del contenido de oxígeno disuelto y del nitrato), también observaron un considerable hundimiento de las correspondientes isolíneas y la advección de agua
Subtropical a la región. Esta última sobrepasó incluso el $50 \%$ de la composición porcentual del agua superficial. La presencia del agua Subtropical se vio confirmada por indicadores biológicos tanto fito como zooplanctónicos (Avaria et al.1989).

El Niño 1997/98 también afectó a la bahía de Valparaíso, manifestándose por un aumento de la temperatura del agua de entre 1 y $2{ }^{\circ} \mathrm{C}$, similar al observado por Prado \& Sievers (1987) durante El Niño 1982/83. A su vez la salinidad de la capa superficial se vio alterada por procesos de dilución, consecuencia de las abundantes precipitaciones derivadas del cambio climático ocasionado por el fenómeno El Niño 1997/98. Por esta causa no fue posible calcular la composición porcentual del agua superficial.

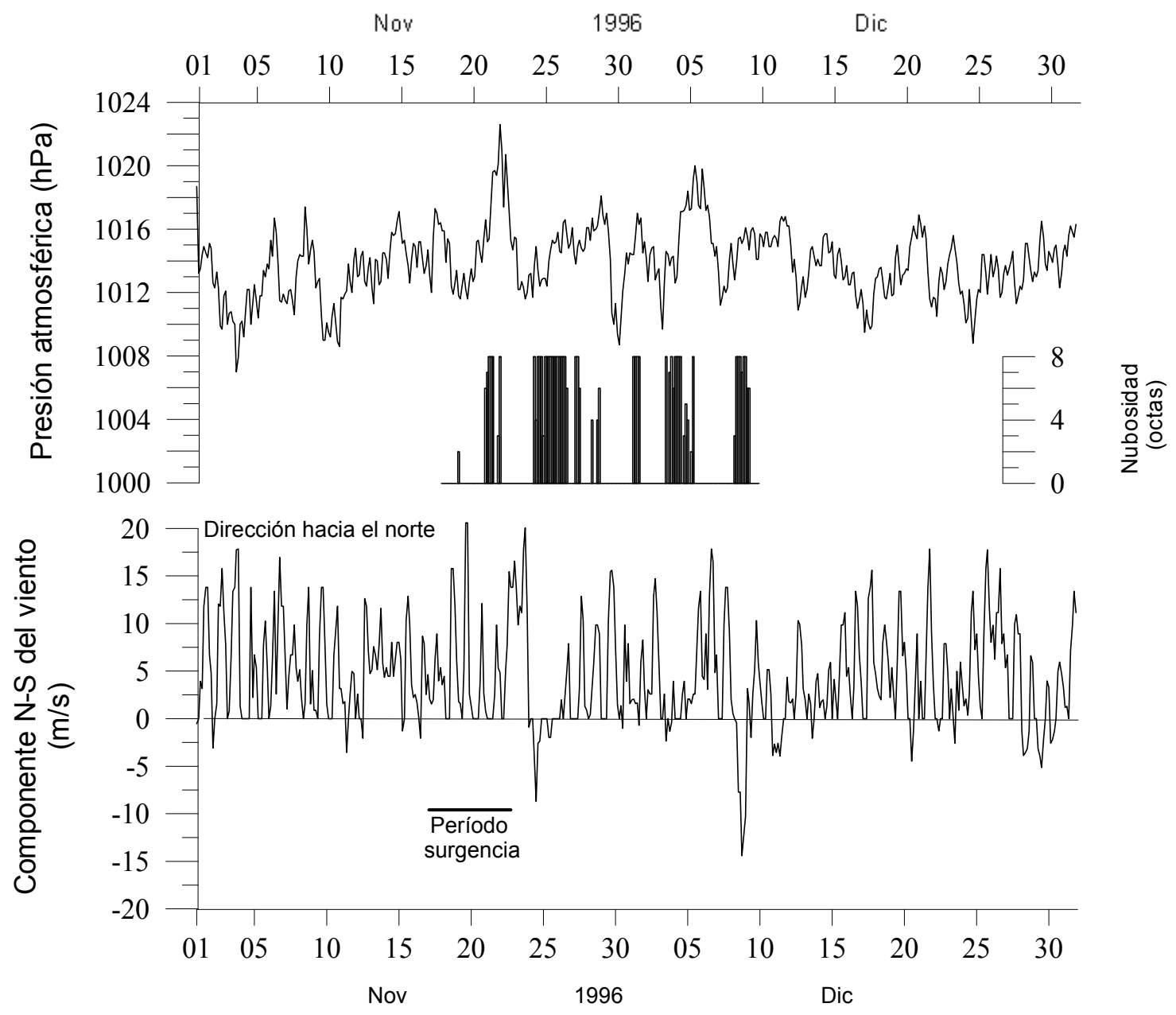

Figura 5

\section{Series de tiempo de presión atmosférica (hPa), nubosidad (octas) y componente $\mathrm{N}-\mathrm{S}\left(\mathrm{m} \mathrm{s}^{-1}\right)$ del viento registrado} en el faro punta Angeles, noviembre-diciembre de 1996.

Time series of atmospheric pressure (hPa), cloudiness (octas) and N-S wind component $\left(\mathrm{m} \mathrm{s}^{-1}\right)$ measured at Punta Angeles lighthouse, November-December 1996. 

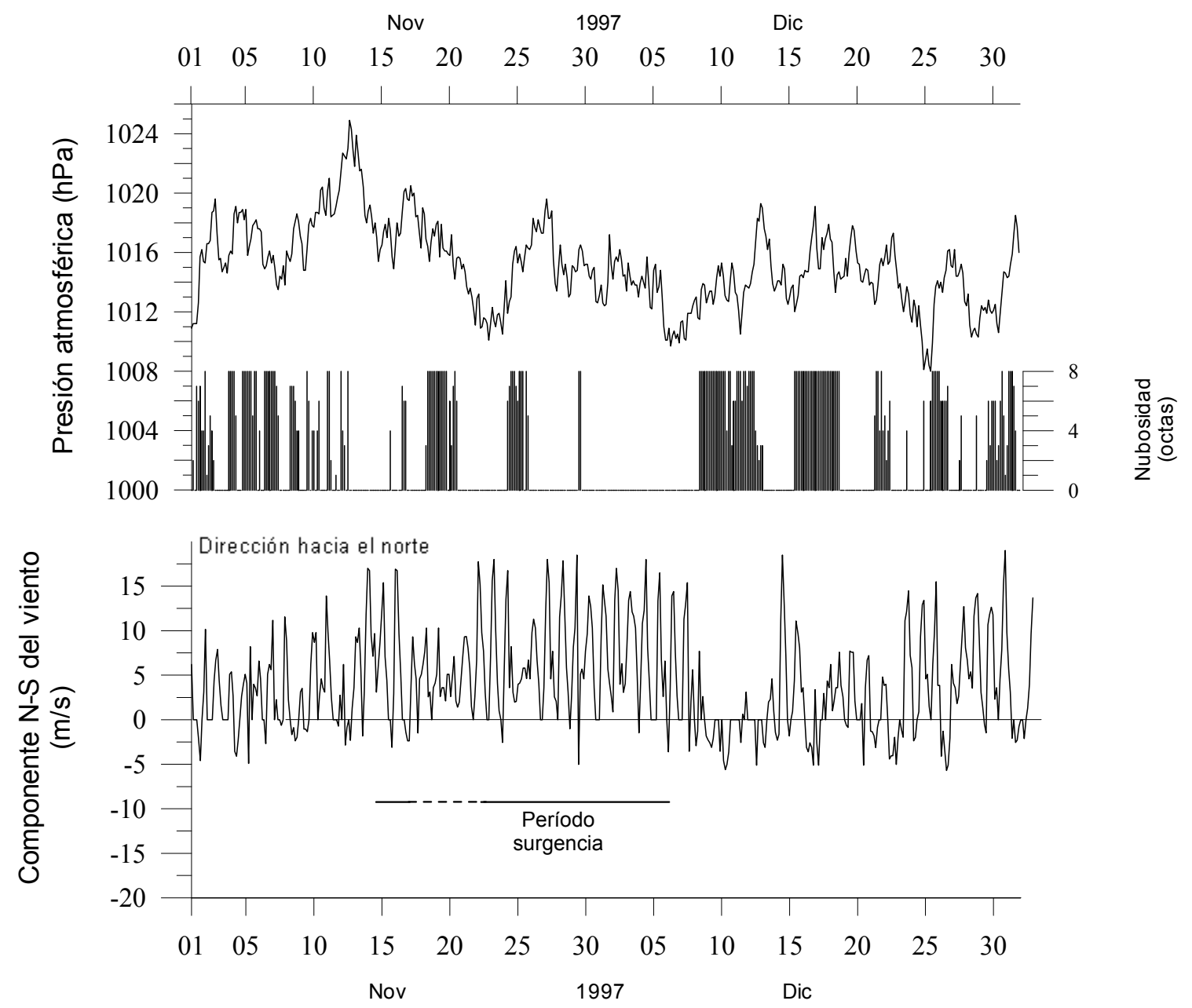

Figura 6

\section{Series de tiempo de presión atmosférica (hPa), nubosidad (octas) y componente $\mathrm{N}-\mathrm{S}$ ( $\mathrm{m} \mathrm{s}^{-1}$ ) del viento registrado en el faro punta Ángeles, noviembre-diciembre de 1997.}

Time series of atmospheric preassure (hPa), cloudiness (octas) and N-S wind component $\left(\mathrm{m} \mathrm{s}^{-1}\right)$ measured at Punta Angeles lighthouse, November-December 1997.

Los efectos de las precipitaciones sobre la bahía de Valparaíso, ya fueran en forma directa como lluvia o por los deshielos estivales habían sido observados en diversas ocasiones anteriores. Silva (1973) y Sievers \& Silva (1979) describieron disminuciones importantes $(<33,9$ PSU) en la salinidad de la capa superficial $(\sim 5 \mathrm{~m})$ en aguas cercanas a la costa ( 1 a 2 millas) en la región de punta Curaumilla-punta Ángeles, como consecuencia de lluvias muy intensas.

También Prado \& Sievers (1987) comprobaron que las aguas superficiales, en la región de Quintero, se vieron alteradas por dilución causada por un gran aporte de agua dulce proveniente del río Aconcagua, consecuencia de abundantes precipitaciones y fuertes deshielos cordilleranos en la época estival asociadas a la ocurrencia del fenómeno El Niño 1982/83.
A pesar de estas alteraciones en 1997, temperatura media más alta y salinidad en momentos muy baja, se pudo observar que durante la fase de madurez de la surgencia costera, los valores superficiales más bajos en temperatura, al igual que las concentraciones de salinidad y la densidad, fueron similares en ambos años (Figs. 2, 3 y 7). Esto indica que los efectos de los procesos de surgencia en la bahía fueron de la misma naturaleza en ambos períodos, sujetos al forzamiento de los vientos, y que su régimen de ocurrencia no fue alterado como sucede en otras regiones cuando se presenta un fenómeno El Niño.

\section{Efectos del río Aconcagua}

Estudios realizados en la bahía de Concón y zona de Montemar, consignados en series de informes no 
publicados de la Facultad de Ciencias del Mar de la Universidad de Valparaíso, han permitido conocer los efectos que un aumento de caudal del río Aconcagua produce en la región de Valparaíso (ie: Sievers \& Soto 1981, Sievers 1988, Sievers \& Prado 1984 y 1990). Dichos estudios han estado sujetos a dos limitaciones importantes: no ha sido posible medir directamente el caudal del río en su desembocadura para determinar la cantidad de agua que efectivamente ingresa al mar en Concón y no se dispone de información respecto a la concentración de nutrientes en las aguas del río en época de gran caudal.

Una evaluación del caudal, si bien indirecta y aproximada, ha sido la de utilizar las mediciones diarias de la Dirección Regional de Aguas de la Región de Valparaíso en la estación fluviométrica Chacabuquito. Las variaciones de caudal registradas en dicha estación, situada a una altura de $1030 \mathrm{~m}$ sobre el nivel del mar, sólo prestan utilidad como orientación general de lo que podría estar sucediendo en la desembocadura. Se ignora el gasto por riego y embalse de las aguas del río a lo largo de su curso y el aumento del caudal por aportes adicionales de su hoya hidrográfica. A pesar de ello se estimó que en momentos de gran caudal, como sucedió en la primavera de 1997, el gasto de agua durante el flujo del río entre Chacabuquito y la desembocadura debería ser proporcionalmente bajo respecto al caudal total, reflejando en sentido correcto las condiciones dables de esperar en la desembocadura. Este no es el caso en un año seco, en que a la natural escasez de agua debe sumarse el consumo para agricultura, agua potable, minería y otros usos. Por lo anterior llega muy poca agua hasta el mar, como puede observarse a simple vista en la desembocadura.

El flujo medio, registrado en Chacabuquito durante el año seco 1996 fue muy bajo y casi constante (entre 10 y $20 \mathrm{~m}^{3} \mathrm{~s}^{-1}$ ), por lo que prácticamente no existió aporte del río Aconcagua a la bahía de Concón. En cambio, en la primavera de 1997 este aumentó mucho debido principalmente, a los deshielos cordilleranos. En dicha época se registró un flujo aproximadamente nueve veces mayor en Chacabuquito, flujo que estuvo sujeto a grandes fluctuaciones con máximos en diciembre (Fig. 7a). El mayor caudal $\left(161 \mathrm{~m}^{3} \mathrm{~s}^{-1}\right)$ se registró el 9 de dicho mes.

En la misma Fig. 7 se pueden apreciar las alteraciones, algunas bastante importantes, en los valores de las características superficiales del agua en la bahía de Valparaíso, consecuencia de una combinación de efectos de la surgencia, El Niño y el caudal del río Aconcagua. En las figuras se han resaltado, representados por trazos, los períodos de los episodios de surgencia. Al respecto cabe recordar que en 1996 la surgencia estaba en desarrollo al iniciarse las observa- ciones, proceso que posiblemente se había iniciado el día anterior y que finalizó el 24 de noviembre. Se puede concluir, por lo tanto, que dicha surgencia se prolongó por un período de 7 días (Fig. 5). A su vez se pudo comprobar de los registros de vientos en 1997, que éstos fueron de intensidades muy similares a los del año anterior pero que se mantuvieron por un tiempo más prolongado alargándose el proceso a 15 días (Fig. 6).

En general, las variaciones en los valores de las características siguieron patrones parecidos entre uno y otro año, con las notables excepciones en la salinidad y el silicato (Fig. 7c y f). En temperatura y concentración de fosfato se alcanzaron valores bastante similares hacia el período final del proceso siendo la temperatura algo menor en 1997, consecuencia de una surgencia más prolongada (Fig. $7 \mathrm{~b}$ y d). Con excepción de dicho período de surgencia se apreció también el efecto del fenómeno El Niño, reflejado en las temperaturas superficiales más altas (Fig. 7b). Fosfato y nitrato, si bien siguieron patrones de distribución bastante similares en ambas temporadas, presentaron concentraciones más altas en 1997 (Fig. 7d y e). Sin embargo donde mejor se reflejó la influencia de las aguas del río Aconcagua fue en la salinidad y el silicato. Estas características presentaron distribuciones superficiales bastante homogéneas en 1996, en cambio estuvieron sujetas a grandes variaciones, incluso interdiarias, al año siguiente. Las mayores variaciones, con considerables disminuciones en concentración, se produjeron en salinidad (Fig. 7c). La disminución inicial estuvo en fase con el aumento del caudal del río. A su vez, la considerable baja del 21 de noviembre se debió, seguramente, a que el relajamiento del viento permitió que más agua del río se desviara hacia el sur produciendo la dilución registrada en la estación 6 . Por otra parte, el aumento de la salinidad del 26 está relacionado con el proceso de surgencia, debido al cual agua Ecuatorial Subsuperficial de alta salinidad ascendió hasta la superficie (Fig. 4b). Las fluctuaciones posteriores no presentaron asociaciones similares con el régimen de vientos o procesos de surgencia pero sí reflejaron, de alguna manera, el considerable aumento del caudal del río en diciembre.

El silicato también presentó concentraciones que inicialmente, hasta el comienzo del proceso de surgencia, siguieron un patrón similar al del nitrato (Fig. 7e y f). Sin embargo, a medida que fue progresando la surgencia y aumentando el caudal del río Aconcagua también fue aumentando su concentración hasta alcanzar un máximo de 48,9 $\mu \mathrm{mol} \mathrm{dm} \mathrm{dm}^{-3}$ (Tabla 1 y Fig. $7 \mathrm{f}$ ). Posteriormente, y a pesar de haberse mantenido un caudal alto la concentración del silicato disminuyó considerablemente, incluso en momentos en que las otras sales nutrientes mostraban un nuevo aumento. Dos 

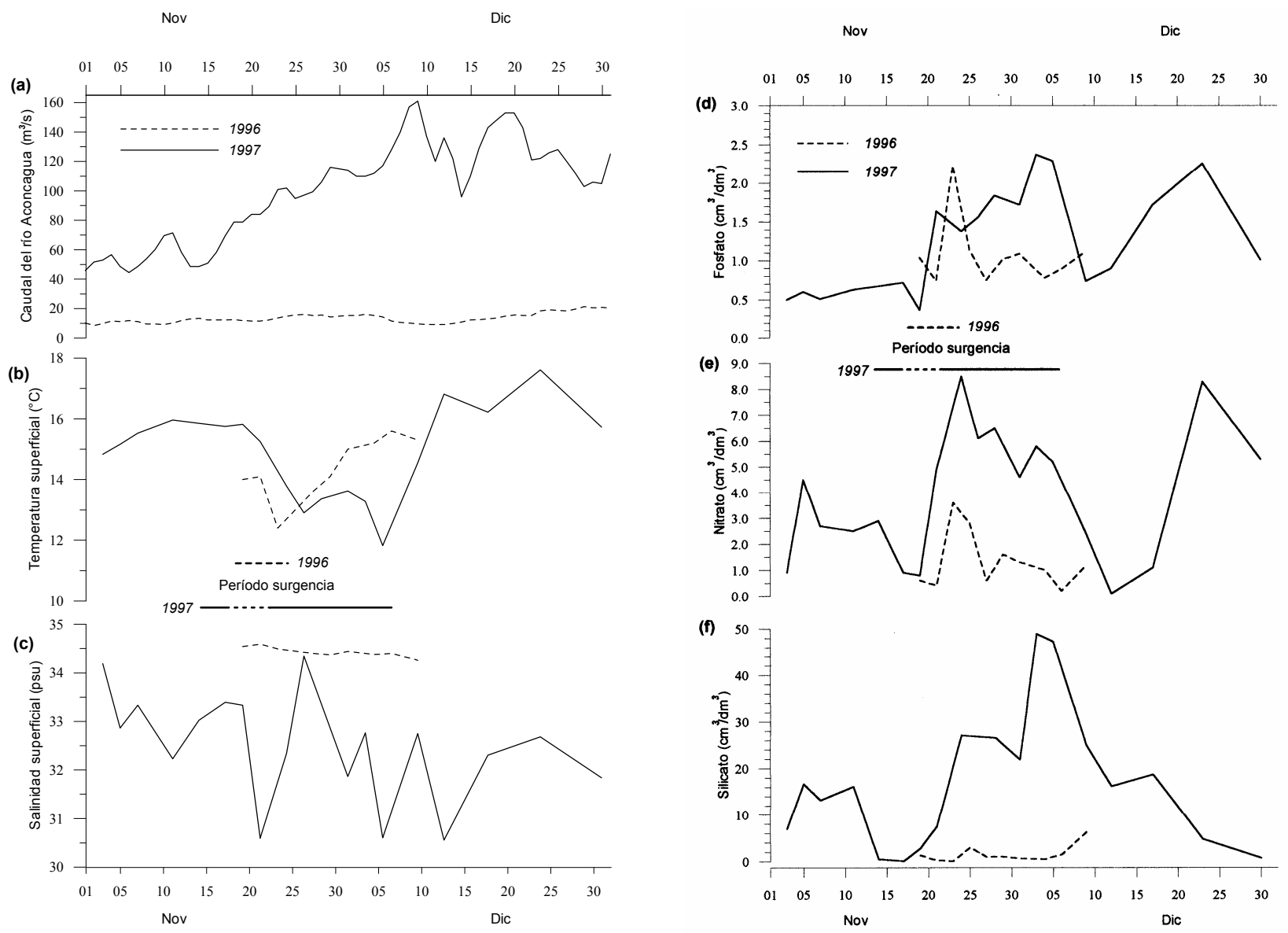

\section{Figura 7}

Series de tiempo (a) caudal medio diario $\left(\mathrm{m}^{3} \mathrm{~s}^{-1}\right)$ del río Aconcagua medido en Chacabuquito, $y$ valores superficiales de (b) temperatura ( $\left.{ }^{\circ} \mathrm{C}\right)$, (c) salinidad (PSU), (d) fosfato $\left(\mu \mathrm{mol} \mathrm{dm}{ }^{-3}\right)$, (e) nitrato $\left(\mu \mathrm{mol} \mathbf{d m}^{-3}\right)$ y (f) silicato $\left(\mu \mathrm{mol} \mathrm{dm}{ }^{-3}\right)$, en estación 6, noviembre-diciembre de 1996 y 1997.

Time series of (a) daily average Aconcagua River flow $\left(\mathrm{m}^{3} \mathrm{~s}^{-1}\right)$, measured at Chacabuquito, and surface values of (b) temperature $\left({ }^{\circ} \mathrm{C}\right)$, (c) salinity (PSU), (d) phosphate $\left(\mu \mathrm{mol} \mathrm{dm}{ }^{-3}\right)$, (e) nitrate $\left(\mu \mathrm{mol} \mathrm{dm}{ }^{-3}\right)$ and (f) silicate $\left(\mu \mathrm{mol} \mathrm{dm} \mathrm{dm}^{-3}\right)$ at Station 6 , NovemberDecember 1996 and 1997.

causas pueden haber influido en esta baja, pero no necesariamente explican todo el proceso. Una se refiere al consumo de silicato por diatomeas, que presentaron floraciones importantes en esa época del año (Muñoz, com. per.). La otra, una disminución o una mayor dispersión de los sedimentos arrastrados al área de observación a pesar del alto caudal. En todo caso hacia fines de diciembre el silicato había disminuido tanto en la superficie como en la columna de agua.

\section{Conclusiones}

Agua Ecuatorial Subsuperficial, que se caracteriza por bajos valores de temperatura y oxígeno disuelto y alta salinidad y nutrientes, ingresa a la bahía de Valparaíso cuando ocurren episodios de surgencia en punta Curaumilla.

Aún cuando la temperatura en 1997 (año Niño) fue más alta que en 1996 (año frío) sus valores superficiales más bajos, al igual que los más altos en salinidad, fueron similares en momentos de intensos procesos de surgencia.

Salinidad y nutrientes presentaron diferencias notorias en concentración superficial entre uno y otro año, siendo la primera más baja y los segundos más altos en 1997, en clara relación con el considerable aumento de caudal del río Aconcagua.

Complejas interacciones entre determinadas condiciones iniciales y las distintas fases de los procesos de surgencia, los campos de presión y viento, el flujo 
estuarino, las fluctuaciones del fitoplancton donde priman las diatomeas, entre otros factores causan fuerte variabilidad en las características físico-químicas en la bahía de Valparaíso.

\section{Agradecimientos}

Se agradece muy sinceramente a las instituciones que se indican por la colaboración prestada: Servicio Hidrográfico y Oceanográfico de la Armada por los análisis de salinidad; Dirección Regional de Aguas, Región de Valparaíso por los datos de caudal del río Aconcagua; Servicio Meteorológico de la Armada por la información meteorológica. Asimismo se agradece la colaboración de los técnicos del Instituto de Oceanología Srs. Juan Soto, Sergio Zepeda y Juan Ayala por las mediciones y tomas de muestras; Sras. Antonieta Jojot y Viviana Ríos por los análisis del oxígeno disuelto y nutrientes y al Sr. René Astudillo por el trazado final de los gráficos.

* Proyecto DIUV 3/96, financiado por la Dirección de Investigación y Postgrado de la Universidad de Valparaíso.

\section{Literatura Citada}

Avaria S, S Palma, HA Sievers \& N Silva. 1989. Revisión sobre aspectos oceanográficos físicos, químicos y planctológicos de la bahía de Valparaíso y áreas adyacentes. Biología Pesquera 18: 67-96.

Brandhorst W. 1963. Descripción de las condiciones oceanográficas en las aguas costeras entre Valparaíso y el golfo de Arauco, con especial referencia al contenido de oxígeno y su relación con la pesca (resultados de la Expedición AGRIMAR). Ministerio de Agricultura, Dirección de Agricultura y Pesca, Santiago, Chile, 55p.

Brandhorst W. 1971. Condiciones oceanográficas estivales frente a la costa de Chile. Revista de Biología Marina, Valparaíso 14 (3): 45-84.

Calderón JE. 1998. Descripción de los eventos de surgencia en la bahía de Valparaíso durante el pasaje de depresiones costeras $\left(33^{\circ} \mathrm{S}\right)$. Tesis para optar al título de Meteorólogo, Universidad de Valparaíso, $67 \mathrm{p}$.

Carrit DE \& JH Carpenter. 1966. Comparison and evaluation of currently employed modifications of the Winkler method for determining dissolved oxygen in sea water; a NASCO Report. Journal of Marine Research 24: 286-318.

Fonseca T. 1977. Proceso de surgencia en punta Curaumilla, con especial referencia a la circulación. Tesis para optar al título de Oceanógrafo, Universidad Católica de Valparaíso, $90 \mathrm{p}$.

Fonseca T \& V Hickmann. 1978. Contribución al conocimiento de las condiciones oceanográficas de la bahía de Valparaíso. Investigaciones Marinas, Valparaíso 6 (5): 73-86.
Fonseca TR \& M Farías. 1987. Estudio del proceso de surgencia en la costa chilena utilizando percepción Remota. Investigación Pesquera (Chile) 34: 33-46.

Fonseca T, MA Barbieri, H Olguín, S Palma, N Silva \& M Toledo. 1988. Eventos de surgencia en la zona de Valparaíso y sus efectos en el ecosistema marino. Informe final FONDECYT 1180/85, $137 \mathrm{p}$

Grasshoff K. 1983. Determination of nitrate. En: Grasshoff, K, M. Ehrhardt \& K Kremling, (eds.), Methods of Seawater Analysis, 2 ${ }^{\text {nd }}$ Ed.: 143-150. Verlag Chemie, Weinheim, Federal Republic of Germany.

Johnson DR, T Fonseca \& HA Sievers. 1980. Upwelling in the Humboldt Coastal Current near Valparaíso, Chile. Journal of Marine Research 38 (1): 1-16.

Koroleff F. 1983. Determination of phosphorus. En: Grasshoff K, M. Ehrhardt \& K Kremling, (eds.), Methods of Seawater Analysis, $2^{\text {nd }}$ Ed.: 125-139. Verlag Chemie, Weinheim, Federal Republic of Germany.

Masotti IM. 1999. Sinopsis satelital y oceanográfica de un proceso de surgencia y su relación con la variación del fitoplancton superficial en la bahía de Valparaíso, Chile. Tesis para optar al título de Biólogo Marino, Universidad de Valparaíso, $117 \mathrm{p}$.

Montecinos A \& F Balbontín. 1993. Indices de surgencia y circulación superficial del mar: Implicaciones biológicas en un área de desove de peces entre Los Vilos y Valparaíso, Chile. Revista de Biología Marina 28 (1): 133150.

Pizarro M. 1976. Estudios de ecología fitoplanctónica en la bahía de Valparaíso. IV. Condiciones físicas y químicas del ambiente. Revista de Biología Marina, Valparaíso 16 (1): 35-69.

Prado R \& HA Sievers. 1987. Distribución de características físicas y químicas frente a península Los Molles, Chile $\left(32^{\circ} 45^{\prime} \mathrm{S}\right)$ y su relación con el fenómeno "El Niño" 1982/83. Revista de Biología Marina, Valparaíso 23 (1): $31-75$.

Sievers HA. 1988. Oceanografía En: Programa de Investigación, vigilancia y control de la contaminación marina por hidrocarburos de petróleo en el Pacífico sudeste y su efecto en las comunidades y ecosistemas marinos, 5-44. CONPACSE - Fase 1. Informe de avance $\mathrm{N}^{\circ}$ 3, Doc: IOUV /3/ agosto 1988. Instituto de Oceanología, Universidad de Valparaíso, presentado a la Comisión Permanente del Pacífico Sur (CPPS), 192 p.

Sievers HA \& N Silva. 1973. Variaciones estacionales de temperatura, salinidad y contenido de oxígeno frente a la bahía de Valparaíso (mayo 1968-abril 1969). Investigaciones Marinas 4 (1): 1-16.

Sievers HA \& N Silva. 1979. Variación temporal de las condiciones oceanográficas frente a punta Curaumilla, Valparaíso, Chile (mayo de 1974 - abril de 1975). Investigaciones Marinas 7 (1): 3-20. 
Sievers HA \& MA Soto. 1981. Oceanografía En: Vigilancia de variaciones climatológicas y bio-oceanográficas en la zona de Quintero, Chile (L. $32^{\circ} 45^{\prime} \mathrm{S}$ ) en relación al fenómeno "El Niño", 10-28. Informe de Avance $\mathrm{N}^{\circ} 1$. Instituto de Oceanología, Universidad de Valparaíso, presentado al Comité Oceanográfico Nacional (CONA), $110 \mathrm{p}$.

Sievers HA \& R Prado. 1984. Oceanografía En: Vigilancia de variaciones climatológicas y bio-oceanográficas en la zona de Quintero, Chile (Latitud 32 $45^{\prime} \mathrm{S}$ ) en relación al fenómeno "El Niño": 27-56. Informe Final. Instituto de Oceanología, Universidad de Valparaíso, presentado al Comité Oceanográfico Nacional (CONA), 473 p.

Sievers HA \& R Prado. 1990. Oceanografía En: Variabilidad ambiental y biológico - marina frente a Valparaíso, Chile: 18-30. Informe Final. Informes Científicos y Técnicos, Instituto de Oceanología, Universidad de Valparaíso, 11/90, presentado al Comité Oceanográfico Nacional (CONA), $150 \mathrm{p}$.
Silva N. 1973. Variaciones estacionales de temperatura, salinidad y contenido de oxígeno en la zona costera de Valparaíso (septiembre de 1969 - agosto de 1970). Investigaciones Marinas, Valparaíso 4 (3): 89-112.

Silva N \& B Ramirez. 1983. Vigilancia de la variación espacio-temporal de las condiciones oceanográficas físicas, químicas y biológicas frente a la bahía de Valparaíso. Estudios y Documentos, Universidad Católica de Valparaíso 10/89, 175 p.

Strickland JDH \& TR Parsons. 1968. A Practical Handbook of Seawater Analysis. Bulletin of the Fisheries Research Board of the Canada 167: 1-311.

Uribe E. 1978. Estudio de las comunidades fitoplactónicas durante un proceso de surgencia frente a punta Curaumilla-Valparaíso. Tesis para optar al título de Profesor de Biología, Universidad Católica de Valparaíso. $65 \mathrm{p}$. 